\title{
New media - opportunity for new and small parties? Political communication before the parliamentary elections in Iceland in 2013
}

\author{
Birgir Guðmundsson, Associate Professor in Media Studies and Political \\ Science, University of Akureyri
}

\begin{abstract}
This article presents results from a survey among political candidates standing in parliamentary elections in Iceland in the spring of 2013 regarding their use of media in the election campaign. The purpose of this study was twofold; first to determine the extent to which politicians have adopted new technologies, thereby adapting their election strategies to new realities and a transformed media environment characterized by hybridization between new networked media and traditional media logic. Secondly, to examine whether in a digitalized media era, there is a difference in media use between old and new political parties. The findings suggest a process of normalization and the potential advantage for new parties, due to easier access to communication channels created by less expensive new media outlets, was by and large negated by a more complex and diverse media environment.
\end{abstract}

Keywords: political communication; Iceland; new media; hybrid media; media; political parties; elections. 


\section{STJÓRNSÝSLA}

\section{Introduction ${ }^{1}$}

This paper looks at political communication in Iceland with a focus on the media use of candidates standing in the 2013 parliamentary elections and their evaluation of the importance of different media gateways. In light of a changing media environment, with the increasing role of online media and in particular social media, a comparison is made of political communication between established parties on the one hand and the large number of new parties that ran in the elections on the other. Bergsson (2014) has shown that in the 2013 election Facebook was by far the most important social media, but that it was mainly used in a one-way fashion by the parties with limited interaction with voters. This paper expands on this and questions how and if a new communication environment affects the possibilities for new parties to contest elections?

The paper begins with a brief overview of the Icelandic media and party systems, followed by a discussion of the scholarly literature on new media and political campaigning. Then research questions, hypotheses, methods and instruments are introduced before survey results are presented and discussed.

\section{Icelandic media and party system}

Iceland is a parliamentary republic, characterized by majority coalition governments. The legislature - Althingi - is a unicameral parliament consisting of 63 members elected with proportional representation in six constituencies. Historically, the present party system dates back to the 1916 -1930 period, when the four main parties were formed. All these parties have ideological counterparts in the European political spectrum, and are: the Independence Party which is a conservative party; the Progressive Party which is an agrarian/centre party; the Alliance which is a social democratic party; and the Left-green Party, which is a left-socialist party (Hardarson 2008). The centre-left parties underwent restructuring in 1999 and the Alliance and Left-green Party were formed on the basis of older parties, called the People's Party and the People's Alliance. These four party types have dominated the Icelandic party system since the 1930s but their hegemony has been challenged in recent decades and since 1971 a variation of two additional parties have most of the time managed to secure representation in the legislature. With the exception of the Women's Alliance, which had representation from 1983 to1995, and the Liberal Party that had a member elected in three consecutive elections from 1999, these additional parties did not receive representation for more than one or two electoral terms.

The four main parties have had a strong position, receiving for extended periods of time more than $90 \%$ of the votes. Until 1967 their share was more than $95 \%$ and aside from a temporary drop in 1971 it was not until the 1980s that the four-party share once more fell below the $90 \%$ limit. After the restructuring of the left in 1999, the four parties once more rose above the 90\% limit, receiving between $89-95 \%$ of the votes. Simultaneously, since the 1980 s electoral volatility has been increasing and about $1 / 3$ of the electorate has changed parties between elections since the 1990s (Hardarson 2008). 
There has however been a dramatic change after the financial collapse in 2008 and the ensuing crisis. In the elections of 2009 the four main parties received some $90 \%$ of the votes, but in 2013 this number fell to $74.9 \%$ (Hagstofa Íslands n.d).

The media system and political communication in Iceland have been transformed in the last two or three decades, a change that has occurred alongside important changes in political and economic conditions. At the turn of the century a market driven media system - for all intents and purposes - replaced traditional political parallelism and signs of professionalization in journalism became a more visible characteristic of the media. In the last three decades of the 20th century the old system of political patronage, politization of media and domination of political parties of all spheres of society was giving way to a more independent and professionalized mode of communication (Hardarson 2008; Gudmundsson 2007). However, the relatively recent introduction of market media and professionalization of journalism, loose regulations by the state and concentration of media ownership, provide the Icelandic system with some special characteristics. As some media owners have, or are perceived to have, political connections, most of the larger media are regarded by political actors to be biased and unprofessional, and hence the situation has been described as a "politically commercial media system" (Gudmundsson 2013). Although politicians perceive the media as biased and unprofessional, there exists considerable plurality and alternative coverage both in print and broadcast media, two major national newspapers and a number of television and radio channels, including the state-owned public service radio and television (Gudmundsson n.d.).

Parliamentary elections in the spring of 2013 saw the participation of an unusually high number of new parties, though the majority of those newcomers would not surpass the $5 \%$ national electoral threshold required for a candidate to be elected (Electoral Commission 2013). Most of the new parties entered the election late and only partially possessed the resources necessary for success, whether in terms of structure and organisation, or communication and finances. The Needs Assessment Mission report of OSCE/ODIHR for the 2013 elections noted that many interlocutors expressed the opinion "that it could be a challenge for the media to cover the campaign due to the large number of parties potentially contesting the elections and the fact that the final number of parties and their candidate lists will be known only two weeks before election day. A few political parties expressed a degree of dissatisfaction with the media's coverage, especially for new political parties“(OSCE/ODIHR 2013, 8).

The parties that are being referred to here as "new parties" are: The Bright Future Party, the Right Green Party, the Household Party, the Rainbow Party, the Democratic Watch Party, the Dawn Party and the Pirate Party. In addition a number of parties/ organisations stood in only one or two constituencies, i.e. the People's Front, the Humanist Party, The Sturla Jonsson Party and the Regional Party, but these parties are not included in this study. 


\section{Transformation of political communication}

Transformation of political communication has had a major impact on both politics and the media. Politics in general and the political parties in particular have had to adapt to a radically altered landscape of media and technology. This transformation refers to increased professionalization and commercialization of the media, online 24/7 coverage and widespread social media use among the public. At the same time the media themselves, both traditional and new, face mutant political realities and circumstances determining the ground-rules of democracy (Dahlgren 2005).

Theoretical discussion of political communication and the democratic role of modern media have drawn attention to the importance of these dramatic changes, but scholars approach the issue from different perspectives (Mancini 2013). The seminal study of Hallin and Mancini (2004) has become a reference point or a landmark in the discussion of political media systems. Their framework is widely used as the basis of comparative studies and it identifies three main types of political systems: the North Atlantic system; the North and Central European system; and the Mediterranean system (Hallin \& Mancini 2004). However, this type of analytic framework only partially captures the impact of technology and social factors such as professionalization on both politics and media (Blumler \& Coleman 2010).

A large part of contemporary scholarly discussion of political communication only relates to this transformation in an indirect manner. Many studies focus on particular aspects and specific details of the change, such as new electioneering methods, or they review particular examples of technical innovation in the election campaign of a certain candidate and the way in which the media react to these examples (Gibson \& McAllister 2011; Nisbet \& Myers 2010). However, this transformation has far-reaching effects on the function, professional awareness and professionalization of journalists and the media in general. Simultaneously, this change has important implications for politics and the way in which it is conducted. The Italian political scientist Paolo Mancini stated already by the turn of the century that the process of professionalization of politics had reached a new frontier. This new frontier constituted a fundamental change in politics and government, where technical experts who operate on an open market had assumed a central place in decision making and the way in which the political game was played. This technological professionalism was of a global nature, although it varied in form from one country to another, but the overall effect was to turn political parties into what Mancini called "communication machines" that sought to manipulate voters and turn politics and decision making into a technical assignment in communication strategy (Mancini 2001).

As the professionalization of electoral campaigns, strategies, parties, candidates and politics in general has become the subject of scholarly study, the professionalization of the coverage of professionalized politics has also been studied. Esser, Reinemann, and Fan (2001) suggested a theory of "metacommunication", which was based on a cross-country content analysis of spin doctors in the press. This refers to a new style of reporting that takes into account the interaction between political public relations 


\section{STJÓRNSÝSLA}

on the one hand and political journalism on the other. Indeed, empirical comparative research also suggests that a split between professional groups, i.e. between the media and political actors, transcends national boundaries in Europe (Pfetsch 2014).

An important element of this ongoing professionalization of political communication is the advent of associated digital media and communication possibilities. First came the basic options offered by the Internet (web 1.0) and later the interactive possibilities associated with web 2.0 technologies. This development has been somewhat uneven, without clear-cut stages and therefore a relatively broad term is needed to define the difference between these online communication techniques and traditional media. Thus the term "new media" is used in this paper to refer to this process and is used in a fairly broad sense, including both web 1.0 and web 2.0 technologies (here also web 1.5 technology which can be seen a half way between the two), i.e. general internet sites, blogs and social media. ${ }^{2}$

An early interpretation of the effects of online communication emphasized what might be labelled as a positive or liberating dimension of new internet technologies i.e. allowing for a dialogue between politicians and their electorates (Larson \& Svenson 2014). This also includes the possibilities for citizens to express themselves freely in blogs and social media thereby becoming direct participants in the digital public sphere. Democratic empowerment is seen in how traditional media establishments and the hierarchical structure that controls the agenda of social discussion are bypassed (Gilmour 2004). The relatively low cost barrier and potential reach of online communication gateways would be of interest not just to bloggers and private individuals but also to smaller and new political actors possibly resulting in more equal opportunities in the political arena (Larsson 2014). Tentative support for this claim can be detected in the disproportionately high twitter use of political "underdogs" or smaller political actors reported by Larson and Moe (2014) in the 2011 and 2013 Norwegian elections.. However, as the authors point out, at the time Twitter was an elite medium and no definite conclusions could be made on the equalizing effects of twitter (Larson and Moe 2014).

In spite of the broad number of new media outlets and myriad possibilities for individuals and groups to express themselves, reality dictates that new media no less than traditional are subject to considerable limitations in the dissemination of political discussion. Empirical research suggests that while this new form of communication may be equally accessible to all candidates standing in an election, those with greater resources and financial capabilities are more likely to successfully utilize these media than candidates with more limited resources (Sudulich \& Wall 2010). Thus offline inequalities are reflected in the differences in parties' online strategies. This was demonstrated by Lilleker, et. al. (2011) in their comparative study of the 2009 elections in France, Germany, UK and Poland which showed that established major political parties led in interactive and innovative campaigning. New media thus does not even out the disadvantages faced by candidates from a poorer social and economic situation (Ammann 2010; Peterson 2012). In this respect, the same is true of social media and the internet in general: contrary to what many had anticipated, greater and more equitable 
access to the Internet did not result in a more equal position of political actors (Small 2010).

The above differences in approach to the impact of the internet and its evolution on political communication can be characterized in terms of a dichotomy: the innovation (equalization) hypothesis and the normalization hypothesis. The former entertains the view that the new technology does bring fundamental changes and new opportunities in political communication. The latter sees the Internet as a product of established social and political realities which are replicated in the use of new technology that in turn is normalized (Schweitzer 2008, 2011; Gibson et.al. 2008; Lilleker et.al. 2011; Larson \& Svenson 2014; Larson 2014).

A study on political communication in the digital age in Iceland and Norway (Gudmundsson 2014) reports that traditional political parties have accumulated extensive professional expertise in the use of traditional media and incorporated new internet-based media in their communications both internally and externally. This is in line with the normalizing tendency found in other Nordic, European (Lilleker et.al. 2011; Strandberg 2013; Tenscher 2013) and Anglo-American countries (Gibson et.al. 2008; Gulati \& Williams 2012). This rhymes with Negrine's conclusion (2008) that political parties adopt and apply new communication technologies if they strengthen their position vis-à-vis political rivals. The advent of digital technology is in this respect similar to other large steps in the development of communication technology e.g. radio and television.

Indeed, ground breaking innovations such as radio and television had important implications for political communication and social institutions. The concept or theory of media logics explains how the norms, nature and routines of the media (television) shape and penetrate other areas of social life and institutions (Altheide \& Snow 1979; Chadwik 2013; Klinger \& Svenson 2014). Thus media logic, originally used in singular, referred to the construction of social reality through interaction of social institutions with operational characteristics of the powerful formal media (e.g. genres, templates, narratives, framing and formats). Today, however, with a considerably more complex and diversified media, it is suggested that the difference between media types results in correspondingly different media logics. In particular it is argued that new media on the one hand and traditional media on the other generate distinct media logics. Klinger \& Svenson (2014) analysed the difference in terms of production, distribution, and use between social media platforms and traditional mass media and suggested a new type of media logic, a network media logic that coexists and interacts with older traditional mass media logic. Through this approach they sought to go beyond the determinism of the dichotomy of the innovation and normalizations hypotheses as both old and new media logics, network media and traditional mass media logics, coexist and in some ways overlap (Klinger \& Svenson 2014). This approach is in line with Chadwick's powerful thesis on a hybrid media system where power is determined by a successful use, for one's own goals, of information flows "across and between a range of older and newer media settings” (Chadwick 2013, 207). 
I have shown how newer media practices in the interpenetrated fields of media and politics adapt and integrate the logics of older media practices in those fields; and, conversely, how older media practices in the fields of media and politics adapt and integrate the logics of newer media practices ... Though there are important constraints on the power of non-elites, and the logics of older media continue to be powerful in shaping politics, the opportunities for ordinary citizens to use the hybrid media system to influence the form and content of public discourse are, on the balance, greater than they were during the stultifying duopoly of broadcasting and newspaper logics (Chadwick $2013,210)$.

Although the aforementioned study of political communication in Norway and Iceland (Gudmundsson 2014) does not explicitly refer to a hybrid media system it clearly describes closely related tendencies. In this study five general dimensions were found to characterize the new realities of political communication. These were: agenda setting; targeting of special groups; internal communication; professionalization; and a holistic communication strategy (Gudmundsson 2014).

These dimensions indicate that if parties intend to compete successfully for votes they need to capability, expertise, human and financial resources, and the ability to operate "across and between a range of older and newer media settings" (Chadwick 2013, 207). Gudmundsson (2014) found that in Norway and Iceland long-established parties, namely party organizations with structure and experience from previous elections, have developed communication strategies and techniques incorporating both traditional and new media. As Web 2.0 matured major party organizations in Norway seem already to have been in control of the technology by the 2009 elections (Kalnes 2009).

Indeed this is how professionalization of politics has developed, with communication experts continuously looking for new ways to disseminate political messages and quickly adjust to and exploit the possibilities of new communication technologies and utilizing different types of networked and traditional mass media logics. New parties, however, are in the long run at a disadvantage as they lack comparable experience and organisational means. They are in this respect less professionalized although such parties might of course be quite varied in nature, with some more at home in traditional mass media logic while others are more geared towards networked media logic. Access to new media, especially social media is by and large equal, however, as shown above, much empirical evidence supports the normalization hypothesis in the Nordic, central European and Anglo-American contexts.

\section{Hypotheses and research questions}

In focusing on Iceland and parliamentary elections in 2013, it is helpful to recall that established parties in Iceland have included new media into their "holistic communication strategies" (Gudmundsson 2014), whereas new parties are more likely to focus on these 
media because of their accessibility. Due to the accessibility of new media, it seems fair to assume that new parties with limited resources would try to make extensive use of these media gateways. Established parties also use the new media, but proportionately newer parties may need to rely to a greater extent on internet sites, social media and a networked media logic in the hope that they can attract the attention of political and journalist elites or the traditional media (Flemming 2013; Larson \& Moe 2014; Gudmundsson 2014). It can be further argued that as it is easier for new parties and their candidates to take advantage of new media than traditional media, then an imbalance between these types of media characterizes their communication strategies thereby supporting:

Hypothesis 1: Political communication of the candidates of new parties in the elections in Iceland in 2013 was based proportionately more on new media and networked media logic than the political communication of candidates from older and more established parties.

Following Hypothesis 1 it can be anticipated, in light of the normalization hypothesis, that in addition to a greater use of new media by new parties, established parties, such as the four parties that have long characterized the party system in Iceland, will also adopt new ways of dissemination and make more extensive use of networking media logic and new media. This generates hypothesis 2:

Hypothesis 2: Candidates of established political parties in Iceland have adapted to the new media and network logic and use it parallel to traditional media in a bybrid media use pattern.

An interesting element of the 2013 election results was that the Pirate Party, which emphasized digital democracy and administrative transparency, did well and managed to have three members elected to parliament. The other new party that managed to get candidates elected was the Bright Future Party who had six members elected. This party also placed an emphasis on organization through the internet and based its structure and policy-making to a large extent on digital interactive communication. Although it might be difficult to demonstrate conclusively that candidates and organizers from these parties were in fact more skilful or able in using new and network media logics than their colleagues from other parties or that their voters were in some way more digitally oriented, the focus of these two parties was on digital organization and digital political communication as a platform for party activity. Furthermore, both these parties presented themselves as exponents of a "new type of politics" that addressed in particular the younger part of the electorate, which is more likely to use new media and be susceptible to networked media logics (Eurobarometer 2011). Thus the question arises whether newcomers in Icelandic politics that openly advocate communication and politics rooted in the innovation hypothesis indeed have at least a partial advantage. In this light, hypothesis 3 is put forth:

Hypothesis 3: The use by Bright Future and Pirate Party candidates of new media and network media logic in the election campaign was relatively more extensive than that of other political parties. 
The above hypotheses revolve primarily around facts concerning media use. In this context, one could distinguish between the media use of the candidates themselves and that of the parties or election campaign offices. Having noted that, the focus in this study is directed towards the politicians themselves. Certainly, the overall integration and dissemination of a campaign program is controlled centrally, but nonetheless the candidates are the actors who elaborate and implement the election program. Likewise, political advertisements are generally controlled centrally at a party office level and not by individual candidates. Therefore the predominant focus of this study is directed towards the types of political communication the candidates themselves emphasize, i.e. which ones they use and which they believe to be important. To put the three hypotheses to a test, two general research questions were posed:

Research question 1: Which media and media gateways did candidates use in the 2013 election campaign?

By asking this question it becomes possible to map the media use of candidates and establish which media and types of media different political actors sought to use in the electoral campaign.

Research question 2: What media and/or media gateways do candidates in the 2013 election campaign believe to be the most important?

This latter question enables an estimation of the importance candidates placed on different media and media types and deepens the information gained by the first question. It also provides important information on how candidates view the importance of and balance between old and new media logics.

\section{Methods and instruments}

A descriptive comparative study was conducted in the form of a web-survey among candidates in all constituencies. The survey was conducted during the election campaign period, from 17-30 April. Election Day was on the $27^{\text {th }}$ of April 2013. Three iterations were sent out, two before Election Day and the last one on Election Day, so that those who had not taken the time to respond could do so after the elections ended.

Questions were asked, about what medium/media candidates used the most to convey their political messages and what medium/media they thought most important. The survey included questions on different areas of the candidate's political communications during the 2013 campaign. Thus the questions discussed here, while within the same context, are therefore a part of a more extensive survey. The two questions specifically examined relate to the use of media by candidates before the parliamentary elections and to their attitudes to the importance of different media. These were closed questions with predetermined options. The questions were:

a) Please indicate how much or little you have/intend to use the following communication channels in your campaign for the upcoming parliamentary elections. (A list of options to be answered on a five point Likert-scale: very much; much; little; very little; not at all.) 
The relevant options dealt with in this paper are:

- Facebook

- Twitter or other social media

- personal blog

- radio

- television

- local media

- other online media

b) In principle, how important or unimportant do you think the following media gateways or media are for getting your political arguments and messages across in the upcoming elections? (A list of options to be answered on a five point Likert-scale: very important; important; neither important nor unimportant; unimportant; very unimportant.)

The relevant options dealt with in this paper are:

- Facebook

- Twitter and other social media

- personal blogs

- radio

- television

- local media

The target population was candidates that stood in the top seats in the elections to Parliament in 2013, i.e. 5-7 top candidates on all the party lists. The intention was to ensure the top 5 candidates of all new party-lists, the top 7 candidates of the more established parties responded to the survey and then to send the survey to all politicians that could reasonably be said to have had at least a theoretical chance of acquiring a parliamentary seat or a substitute parliamentary seat. Eleven parties stood in all electoral constituencies, but a total of sixteen parties or party lists stood in one or more of the six constituencies. In total the survey was sent to 401 candidates, of whom 241 answered or just over $60 \%$. However, as mentioned before, the candidates from parties that only stood in one or two constituencies are not included in this report. ${ }^{3}$ The total number of candidates from parties that stood in all six constituencies that received the survey was 371 , of which 180 or $48.5 \%$ answered the question on which media outlets they used and 151 or $40.7 \%$ answered the question on the importance of different media outlets. It should be stressed in this context, and for the purpose of generalizability, that the survey was not a sample survey, but included the entire target population of political candidates. The division of respondents between parties, sex and age was relatively even and no obvious reason to expect that the respondents would answer in a different manner than the non-respondents. However, as a general reservation it should be noted that when answers are divided between the individual parties in the following 
presentation of results, it is done in percentages and sometimes few candidates lie behind a percentage number. However, for the benefit of comparison between parties a presentation in percentages is chosen, while the total number behind the percentages (N) is also provided.

The web-based program SurveyMonkey was used and the Research Centre at the University of Akureyri sent out and administered the survey.

\section{Results}

As shown in Table 1 the media use of candidates varies by media groups. Facebook was the medium that by far the highest proportion of candidates from all parties reported using much or very much. Over $80 \%$ of the candidates reported that they used Facebook much or very much in the election campaign. All the candidates from the Pirate and Bright Future Parties. Candidates from other parties, including long-established ones such as the Progressive Party, Independence Party and the Left Green Party were not far behind. The same can be said of some new parties such as the Dawn and Rainbow Parties. Apart from Facebook, there does not seem to be much use of social media, and therefore Facebook is reported specifically as it stands out as the most important new media, much more important than e.g. other general online media. It was not surprising that a high proportion of the Pirate Party candidates (73\%) used some sort of online media, while it is interesting and somewhat surprising to note that about $61 \%$ of Independence Party candidates also used online media extensively.

As far as the traditional broadcast media, television and radio, are concerned, there are two things worthy of special attention. The first is the high proportion of candidates from the Independence Party that mentioned this type of media (44\% mention radio and $39 \%$ television), but this rate was much lower among candidates of the other established parties. Secondly, it is the high percentage of candidates of two new parties, the Household Party and the Democratic Watch Party that used radio and television much. Possibly this is due to the uniqueness of the candidates of these parties, as some of the leaders of the Household Party were in fact employees and/or owners of a small metropolitan radio station. Furthermore, various candidates of the Democratic Watch Party were renowned individuals, commentators and artists, who, generally speaking, are more likely than less known people to get the attention of traditional media. 
Table 1. The proportion of candidates from each party that reported using the medium "much" or "very much "in the 2013 election campaign.

\begin{tabular}{lccccccc}
\hline & Local media & Newspapers & Radio & Television & Facebook & Online (other) & $\mathbf{N}=\mathbf{1 0 0 \%}$ \\
\hline Bright Future Party & 62 & 33 & 14 & 10 & 100 & 29 & 21 \\
\hline Progressive Party & 47 & 39 & 6 & 12 & 89 & 29 & 17 \\
\hline Independence Party & 68 & 79 & 44 & 39 & 89 & 61 & 18 \\
\hline Right Green Party & 27 & 38 & 7 & 13 & 83 & 40 & 15 \\
\hline Household Party & 17 & 54 & 50 & 30 & 80 & 30 & 12 \\
\hline Rainbow Party & 20 & 30 & 0 & 11 & 90 & 30 & 10 \\
\hline Democratic Watch P. & 38 & 38 & 46 & 31 & 100 & 38 & 13 \\
\hline Alliance Party & 65 & 35 & 12 & 12 & 82 & 29 & 17 \\
\hline Dawn Party & 21 & 17 & 17 & 22 & 95 & 37 & 18 \\
\hline Left Green Party & 52 & 33 & 23 & 24 & 91 & 32 & 22 \\
\hline Pirate Party & 0 & 36 & 9 & 9 & 100 & 73 & 11 \\
\hline
\end{tabular}

Apart from this, candidates did not seem to attach much weight to these broadcast media in their election campaign, possibly because the opportunities are restricted in this area. Programming in radio and especially in television is highly structured and organized, and the news is, or should be, subject to the professional principles of journalism that politicians can only have a limited influence on.

The possibilities of candidates to make themselves heard in the traditional media are however greater in the print media, national newspapers and local publications. These media are found throughout the country and they accept articles and opinion letters from politicians. Also, they publish news items and feature articles that often relate to political issues. In this context it should be pointed out that candidates from the more established political parties made extensive use of local publications and indeed, candidates from all the established parties except the Independence Party put more weight on local media rather than national newspapers. The importance of newspapers was assessed very differently by candidates and parties, but generally $30-40 \%$ of candidates from each party reported they would use them a lot. The candidates of the Dawn Party did not use newspapers much nor did they focus on the local papers. Only the candidates of the Household and Pirate Parties used local media less, with none from the Pirate Party reporting using a local paper at all.

The relationship between the actual use of communication routes or media gateways by candidates and the confidence they have in them or the importance they place on different media gateways does not go hand in hand. Actually, the results showed a considerable difference, and the difference is greater for some types of media than other. The greatest difference between actual use of a media platform and perceived importance was with broadcast media, in particular television. As shown in Table 2, a high percentage of candidates in most parties considered TV to be important, but far 
fewer (Table 1) said they were taking advantage of it in the election campaign. Similar was the case with the radio, but the gap between the actual use and perceived importance was less than in the case of television. Print media were used by more candidates than broadcast media and in most cases there was a smaller gap between the evaluations of the importance of the print media and their actual use. However, a completely different picture emerged in the case of Facebook. Indeed with five of the eleven parties, a higher proportion of candidates used Facebook much, than believed Facebook to be important.

Table 2. Percentage of candidates from each party that considered the respective medium "important" or "very important".

\begin{tabular}{lcccccc}
\hline & Local media & Newspapers & Radio & Television & Facebook & N=100\% \\
\hline Bright Future Party & 84 & 68 & 74 & 84 & 95 & 19 \\
\hline Progressive Party & 69 & 63 & 63 & 69 & 81 & 16 \\
\hline Independence Party & 89 & 89 & 89 & 89 & 100 & 18 \\
\hline Right Green Party & 83 & 100 & 92 & 92 & 85 & 13 \\
\hline Household Party & 58 & 75 & 92 & 85 & 92 & 12 \\
\hline Rainbow Party & 90 & 80 & 80 & 80 & 80 & 10 \\
\hline Democratic Watch P. & 78 & 80 & 70 & 100 & 90 & 9 \\
\hline Alliance Party & 92 & 75 & 92 & 91 & 92 & 12 \\
\hline Dawn Party & 78 & 78 & 72 & 67 & 94 & 18 \\
\hline Left Green Party & 81 & 81 & 93 & 100 & 73 & 16 \\
\hline Pirate Party & 88 & 88 & 88 & 100 & 100 & 8 \\
\hline
\end{tabular}

Thus there is a significant discrepancy between what media the candidates considered important and what media they actually used. This was especially true for traditional media, but much less for Facebook. Access to traditional media is generally more difficult than to social media and the possibilities for politicians to create or influence content for the traditional media are limited. This point draws attention to the fact mentioned earlier that candidates believe traditional media to be vital (Gudmundsson 2014).

These results do not portray clear patterns regarding the communication routes used by different parties or candidates. Hypothesis 1, presented above suggested that the candidates from new parties put proportionately more emphasis on new media than traditional media, is not supported by the data. Certainly, the new parties did emphasize this type of communication and considered it important. In this way, candidates of the Pirate Party, the Dawn Party, the Rainbow Party and the Right Green Party all placed great emphasis on new media but the Democratic Watch Party, the Household Party and The Bright Future Party all seem to have focused extensively on traditional media as well as new media. A comparison between the mean value for the candidates' use of all types of new media "very much or much" and the mean use of all types of traditional media 
"very much or much" reveals that the use of new media does not depend on whether the party in question is old or new.

This is demonstrated in Figure 1 which shows the ratio between the mean values for the use of candidates of new media on the one hand and their use of traditional media on the other. Those who use new media more than traditional media receive positive numbers, but those who use traditional media more receive a negative number. As demonstrated by the figure, candidates from all parties except the Independence Party and the Household Party use new media more than traditional media. This is particularly evident in the case of the Pirate Party, who stands somewhat out in this respect. Apart from that, the ratio between the uses of different communication routes by candidates is quite similar. In addition, a significant correlation exists between the use of new media and traditional media. Candidates who used traditional media widely, also used new media a lot and vice versa $(r=0.55)$.

Figure 1. The figure shows the differences between the mean values for the use of new media on the one hand and traditional media on the other.

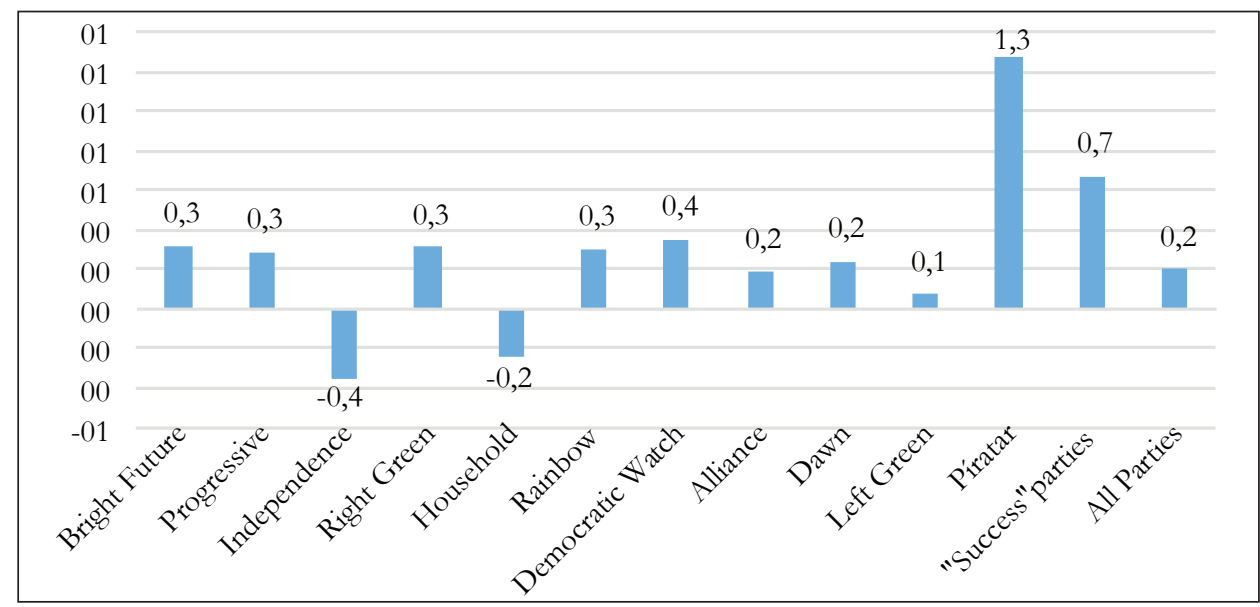

Hypothesis 2 suggested that candidates from traditional political parties in Iceland have adapted to the new media and that these parties take advantage of them simultaneously as they use the conventional media. This is strongly supported by the data (Figure 1). There was a difference between the traditional parties in this respect, but they all used and placed emphasis on both types of media. However, this applies also largely to the new political parties. They put considerable emphasis on traditional media and believed them to be just as important as the long-established parties did. The difference that can be detected between parties does not depend on whether they are established parties or new parties, and there was considerable variation within both groups.

The third hypothesis suggested that candidates from the Pirate Party and the Bright Future Party, which are the new parties that had members elected to parliament, made 
more use of digital dissemination and placed more emphasis on new media than candidates from other parties.

Figure 2. Percentage of candidates of three party groups using the media type in question "much" or "very much".

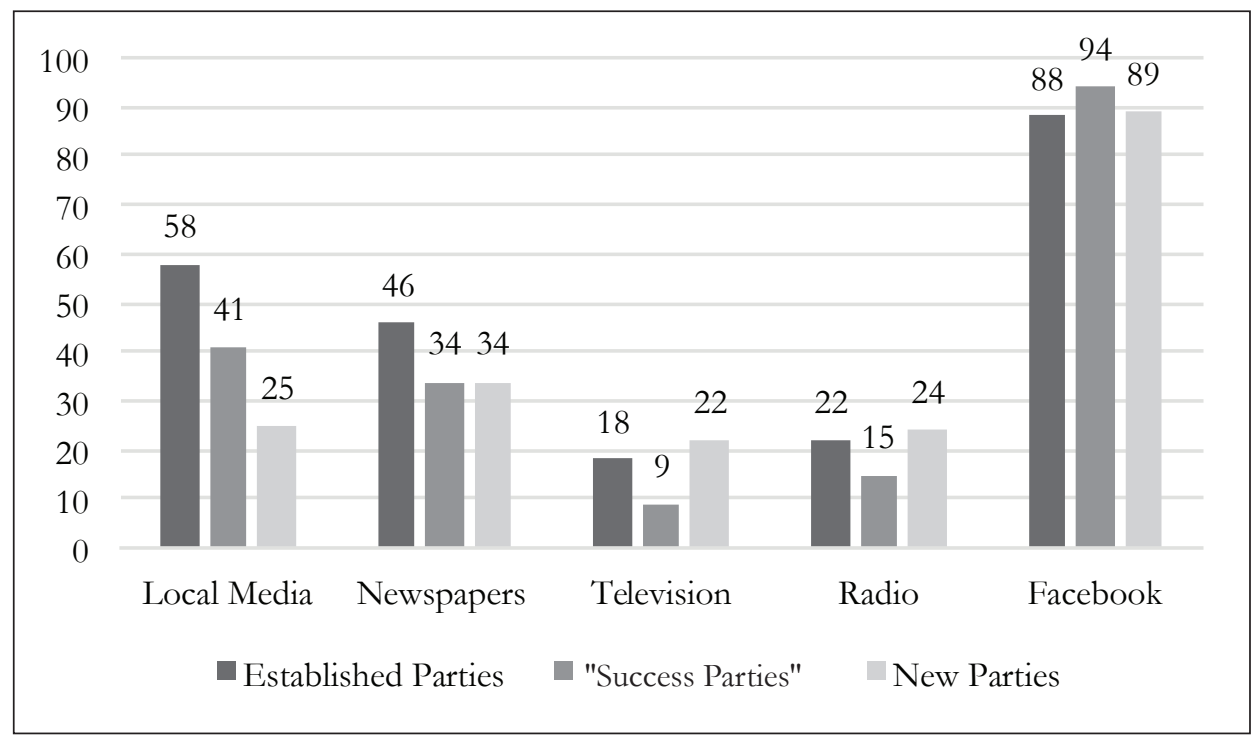

Figure 3. Percentage of the three party groups who say the media type in question "important" or "very important". Here other social media than Facebook, such as Twitter and Instagram, are included. A special option was also available for election debates on television.

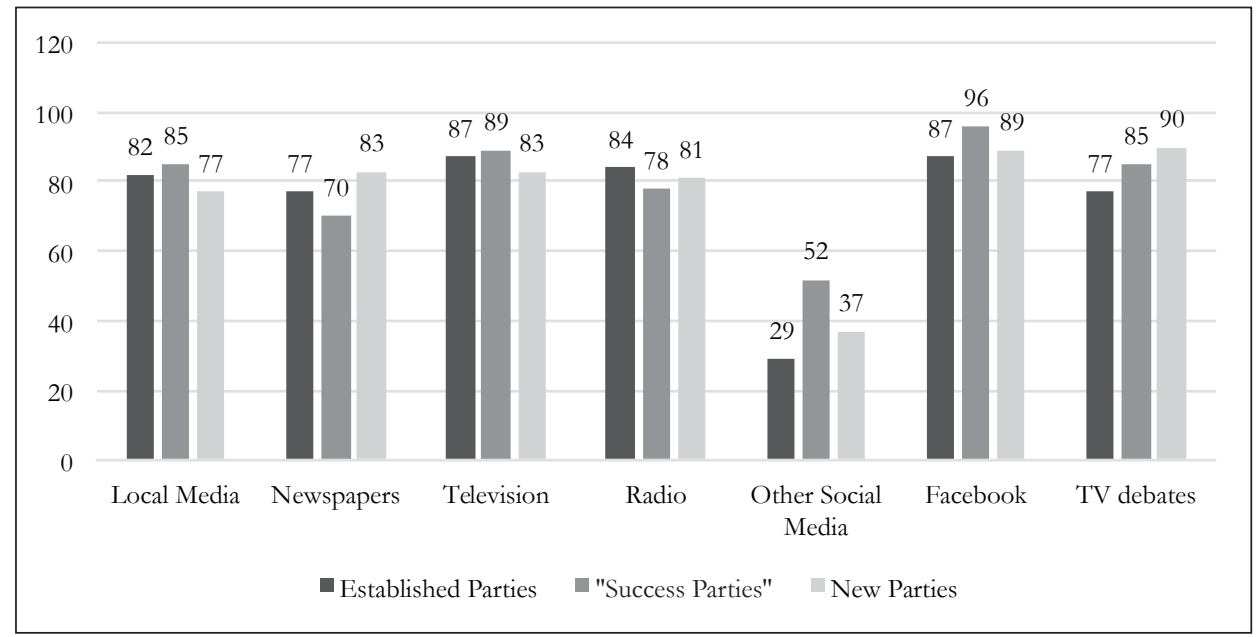


The results partially support this hypothesis, as shown in Figures 1, 2, and 3. They demonstrate that the Pirate Party and the Bright Future Party candidates, which are called here "Success parties", were slightly more focused on Facebook in their campaign (Figure 2) and considered Facebook and other social media slightly more important than did the other party groups (Figure 3). Yet the difference is only marginal and all the parties show a similar pattern in terms of this type of political communication. It should however be noted that although lumped together as "success parties", the Pirate Party stands out more in this respect than does the Bright Future Party. Candidates from the Pirate party are clearly more at home in the network media logic than Bright future candidates and indeed all other candidates, both in terms of use of Facebook and "other online media" (Table 1).

Summarizing, the main results, the following four points emerge. Firstly, it is clear that candidates from new parties took advantage of new media and network media logic and the possibilities these provided and made use of it in the election campaign. Possibly this enabled political newcomers to reach potential voters to a larger degree than otherwise would have been possible.

Secondly, the possible gain of new parties and the potentially equalizing effect of the new media and network media logic is however diminished by the fact that the established parties took extensive advantage of these new media as well.

Thirdly, the network media logic, especially social media, can be seen as an addition to the already complex traditional media flora, and this pattern of a hybrid media system increases complexity across the spectrum of political communication. Thus, despite the low cost and easy access to new media, the increased complexity calls for additional resources to construct comprehensive communication strategies, resources which are rarely available to the new parties or at least not to the same degree as to the established parties.

Fourthly, the enormous use of Facebook is not only due to the politicians' belief in its importance as a medium. Easy access appears also to be relevant in determining why candidates use it so widely. Availability is an important factor, as can be seen in the fact that the candidates thought traditional media important, but still did not use them very much.

\section{Discussion}

In view of the experience of the 2013 elections, the emergence of new media and the explosion in the number of digital media gateways does not seem to have had a greater empowering effect on the disadvantaged new parties and their candidates than on candidates from more established and perhaps more resource rich established parties. In this respect, the findings of the present study seem to add to the empirical data that supports the normalization hypothesis. The media environment has become more complex and fragmented than ever before. Various interactions take place between traditional and new media, which the political parties are aware of and utilize in order to conduct successful political communication. Political dissemination of the digital era 
calls for organization, experience, skills and various other resources which are unlikely to be readily available to new and small parties in the same degree as to traditional established parties. Thus the benefits that the new media bring to new parties in Iceland are countered by the greater potential of the older parties to deal with the higher complexity of the media environment. It might be suggested that the dissemination of the digital communicative innovation has passed the point of a self-sustaining growth or "critical mass", as understood by the theory of diffusion of innovations, and its usage has become the general norm in political communications. That it has reached the top the S-curve with only a few "laggards" still not utilizing new media (Rogers 2003). In his analysis of the development of political communication in Britain, Negrine (2008) suggests that the concept of adaptation is particularly important. Political parties adapt continuously to changing media conditions and there is a continuous creation and recreation of political communication as parties utilize all means available to strengthen their position against competing parties.

This normalization of political communication in face of technological advances is indeed widely noted, e.g. in USA (Gulati \& Williams 2013), in many European countries such as Britain, France, Germany and Poland (Tencher 2013; Lilleker et.al. 2011; Schweitzer 2008; Gibson et.al. 2008) and in Scandinavia (Larson \& Moe 2014; Kalnes 2014; Strandberg 2013). Traditional political parties have certainly not ignored the new media and left it for the new parties to utilize. To the contrary, established parties have embraced them and "recreated" political communication in view of new technologies and opportunities. In addition, it can be assumed that the results presented here underestimate somewhat the focus of established parties on new media, as the data refers to the candidates themselves, but not the central campaign offices that can be expected to place considerable emphasis on new media. Thus, while still recognizing the initial innovative effects of digital communication and social media, this study places the Icelandic political communication condition within a body of later research whose findings "instead suggest a normalization of the offline" (Larson 2014, 3).

At the same time as it becomes apparent that candidates from established political parties make extensive use of social media and other new media, as the normalizations hypothesis suggests, an interesting change can been seen to have occurred in the nature and makeup of the conduct of political communication in Iceland. A change towards a hybrid media system (Chadwick 2013) where two different types of media logics, a more traditional mass media logic and a more recent networked media logic interact (Klinger \& Svenson 2014). This hybridization creates new working practises with new communication gateways while the position of traditional media remains strong and candidates of all parties consider them to be important, more important indeed than their use of them suggests. Journalists and reporters of the traditional media, the gatekeepers, select content and the editing gives this type of media a special status and public value beyond social media or other new media or publications instigated by the parties themselves (Gudmundsson 2014; Flemming 2013). To recap on Chadwick's point cited earlier the public, journalists and politicians interact in this hybrid system and "create, tap, or steer 
information flows in ways that suit their goals and in ways that modify, enable, or disable others' agency, across and between a range of older and newer media settings" (Chadwick 2013, 207)

Although it is unlikely that these changes in political communication have served as an empowering vehicle for electoral success of new and small parties, this new condition has had implications for politics in general. This effect, however perhaps reflects the appearance of politics and how they are practiced. Thus, the use of social media has possibly fuelled a personification of politics, and put individual politicians more at centre stage than before, not only in electoral systems with single-member constituencies, but also to some extent in party-centred systems where party-lists are put forth (Enli \& Skogerbø 2013; Karlsen, 2011). It will however, take further research to establish whether this personifying impact of new media has had similar effects on the partycentred political system of Iceland.

Another point that should be noted concerns the impact of new media and digital technology on Icelandic politics. The Pirate Party's success in the elections and its consequent support in opinion polls where the party has received over an extended period in 2015-2016 an astonishing following of up to 38.6\%, deserves attention (MMR 2016). Although dissatisfaction and protest against established politics and the party system may explain in part at least why the Pirate Party has become a preferred alternative for voters in opinion polls, it seems plausible to suggest that a change in media logic does play a role as well. In particular, in a country like Iceland where the vast majority of the population has a Facebook account (Iceland Review 2013), networked media logic can be seen to fit the on-line lifestyle and ideology associated with the Pirate Party.

To what extent new strategies and hybrid modes of political communication will in the long run impact on Icelandic politics remains to be seen. The adaptability of the established parties to a changing media environment - the creation and recreation of political communication - that was manifested before the 2013 elections, should however underline the importance of viewing such changes in a historical context of a party system and media regime that are in a continuous flux.

\section{Notes}

1 This paper is based upon a conference talk, given at Pjóðarspegillinn, the University of Iceland in 2013.

2 The term "new media" can be seen to be compatable with Chadwick's (2013) thesis of hybrid media and to Klinger \& Svenson's (2014) use of the term "network media logic".

3 The parties that stood in one or two constituencies were very small with a limited structure and received little support. By definition few candidates from these parties received the questionnaire and for the purpose of comparison were omitted from this study.

\section{References}

Altheide, D. L. (2014). Media Edge. Media Logic and Social Reality. New York: Peter Lang Publishing, Inc. Ammann, S. (2010). "Why do they tweet? The use of twitter by US senate candidates in 2010", SSRN Electronic Journal, 12. Available at SSRN: http://ssrn.com/abstract=1725477 or http://dx.doi. org/10.2139/ssrn.1725477 
Bergsson, B. Th. (2014). "Political parties and Facebook: A study of Icelandic political parties and their social media usage", Stjórnmál og sjórnsýsla 10(2), 339-365.

Blumler, J. G. and. Kavanagh, D. (1999). "The third age of political communication: Influences and features", Political Communication 16(3), 209-230.

Blumler, J. G. and Coleman, S. (2010). "Political communication in freefall: The British case and others?" The International Journal of Press/Politics 15(2), 139-154.

Chadwick, A. (2013). The Hybrid Media System. Politics and Power. New York: Oxford University Press.

Dahlgren, P. (2005). "The internet, public spheres, and political communication: Dispersion and deliberation", Political Communication 22(2), 147-162.

Electoral Commission. (n.d.) "Results of election $27^{\text {th }}$ of April 2013." Retrieved 23 $3^{\text {td }}$ of July 2013, from: http://www.landskjor.is/landkjorstjorn/frettir-tilkynningar/nr/122

Enli, G. S. and Skogerbø, E. (2013). "Personalized campaigns in party-centred politics: Twitter and Facebook as arenas for political communication", Information, Communication \& Society 16(5), 757-774.

Esser, F., Reinemann, C. and Fan, D. (2001). "Spin doctors in the United States, Great Britain, and Germany: Metacommunication about media manipulation", The Harvard International Journal of Press/Politics 6(1), 16-45.

Eurobarometer (2011). Standard Eurobarometer 76 "Almenningsálit innan Evrópusambandsins: Skýrsla Ísland", Fall 2011. TNS Opinion \& Social.

Flemming, F. (2013, September). "The interplay of mass media and online campaigning. Evidence from a German state election." Paper presented at the ECREA Conference "New Trends in Political Communication. Evidence, Theories, Implications, Opportunities”, Milano, 19-20 September.

Gibson, R. K. and McAllister, I. (2011). "Do online election campaigns win votes? The 2007 Australian "YouTube" election", Political Communication 28(2), 227-244.

Gibson, R. K., Lusoli, W. and Ward, S. (2008). "Nationalizing and normalizing the local? A comparative analysis of online candidate campaigning in Australia and Britain", Journal of Information Technology \& Politics 4(4), 15-30.

Gillmor, D. (2004). We the media: Grassroots journalism by the people for the people (1st ed.). Sebastopol: O'Reilly.

Gudmundsson, B. (n.d.). "Media Landscapes - Iceland." European Journalism Centre. Retrieved $3^{\text {td }}$ of July 2014 from: http://ejc.net/media_landscapes/iceland

Gudmundsson, B. (2007). "Inngangur - Í spegli tímans", in B. Guðmundsson (ed.) Íslenskir blaðamenn. Reykjavík: Bladamannafelag Islands.

Gudmundsson, B. (2013) "Pólitísk markaðsfjölmiðlun”, Icelandic Review of Politics \& Administration 9 (2), $509-530$.

Gudmundsson, B. (2014). "New Realities of Political Communications in Iceland and Norway", Nordicum-Mediterraneum 9(1). Available at NOME: http://nome.unak.is/wordpress/09-1/c60-article/new-realities-of-political-communications-in-iceland-and-norway/

Gulati, G. J. and Williams, C. B. (2013). "Social media and campaign 2012: Developments and trends for Facebook adoption”, Social Science Computer Review 31(5), 577-588.

Hagstofa Íslands (Statistics Iceland). "Kosningar." Retrieved 18 th of July 2014 from: http://www. hagstofa.is/Hagtolur/Kosningar

Hallin, D. C. and Mancini, P. (2004). Comparing Media Systems. Three Models of Media and Politics. Cambridge: Cambridge University Press.

Hardarsson, O. Th. (2008). "Political Communication in Iceland" in J. Strömback, M. Orsten and T. Aalberg (eds.), Communicating politics. Political Communication in the Nordic Countries (1st ed.). Gothenburg: Nordicom.

Iceland Review (2013) “Iceland Loves Facebook." Retrieved $20^{\text {th }}$ March 2016 from: http:/ /icelandreview. com/stuff/views/2013/04/17/iceland-loves-facebook-job

Kalnes, Ö. (2009). "E-ruptions in Party Politics? The case of web 2.0 and Norwegian parties", Quaderns Del CAC 33, 63-76 
Karlsen, R. (2010). "Online and undecided: Voters and the internet in the contemporary Norwegian election campaign", Scandinavian Political Studies 33(1), 28-50.

Karlsen, R. (2011). "A platform for individualized campaigning? Social media and parliamentary candidates in the 2009 Norwegian election campaign", Policy \& Internet, 3(4), 1-25.

Klinger, U. and Svenson, J. (2014). "The emergence of network media logic in political communication: A theoretical approach", New Media \& Society 1461444814522952 Online first, February 19. Available at: http://nms.sagepub.com/content/early/2014/02/18/1461444814522952

Larsson, A. O. and Moe, H. (2014). "Triumph of the Underdogs? Comparing twitter use by political actors during two Norwegian election campaigns", SAGE Open, October-December 2014, 1-13.

Larsson, A. O. and Svensson, J. (2014). "Politicians online - identifying current research opportunities", FirstMonday, 19(4). Available at: http://journals.uic.edu/ojs/index.php/fm/article/view/4897/3874

Larsson, A. O. (2014). "Online, all the time? A quantitative assessment of the permanent campaign on Facebook", New Media \& Society, June 17. Available at: http://nms.sagepub.com/content/early/2014/06/26/1461444814538798.abstract

Lilleker, D. G., Koc-Michalska, K., Schweitzer, E. J., Jacunski, M., Jackson, N., and Vedel, T. (2011). "Informing, engaging, mobilizing or interacting: Searching for a European model of web campaigning." European Journal of Communication, 26(3), 195 - 213.

Mancini, P. (2001). "New frontiers in political professionalism”, Political Communication 16(3), 231-245.

Mancini, P. (2013). "Media fragmentation, party system, and democracy", The International Journal of Press/Politics 18(1), 43-60.

MMR - Market and media research. (2015). Samfylking og VG mælast með jafnt fylgi. Retrieved $21^{\text {st }}$ of March from: http://mmr.is/frettir/birtar-nieurstoeeur/529-samfylkinginogvgmaelastmedjafntfylgi

Negrine, R. (2008). The Transformation of Political Communication. Continuities and Changes in Media and Politics (1st ed.). New York: Palgrave Macmillan.

Nisbet, E. C. and Myers, T. A. (2010). "Challenging the state: Transnational TV and political identity in the Middle East”, Political Communication 27(4), 347-366.

OSCE/ODIHR (2013). "Iceland Parliamentary Elections 27 April 2013.” OSCE/ODHIR Needs Assessment Mission Report 25-28 February 2013.

Pfetsch, B. (Ed.). (2014). Political Communication Cultures in Western Europe. Attitudes of political actors and journalists in nine countries. New York: Palgrave Macmillan.

Peterson, R. D. (2012). "To tweet or not to tweet: Exploring the determinants of early adoption of twitter by house members in the 111 th congress", The Social Science Journal 49(4), 430-438.

Raoof, J. K., Zaman, H. B., Ahmad, A. and Al-Qaraghuli, A. (2013). "Using social network systems as a tool for political change", International Journal of Physical Sciences 8(21), 1143-1148.

Schweitzer, E. J. (2008). "Innovation or Normalization in E-campaigning? A longitudinal content and structural analysis of German party websites in the 2002 and 2005 national elections", European Journal of Communication 23(4), 310-327.

Schweitzer, E. J. (2011). "Normalization 2.0: A longitudinal analysis of German online campaigns in the national elections 2002-9”, European Journal of Communication 26(4), 449-470.

Small, T. A. (2010). "Canadian Politics in 140 Characters: Party Politics in the Twitterverse", Canadian Parliamentary Review 33, 39 -45.

Strandberg, K. (2009). "Online campaigning: An opening for the outsiders? An analysis of Finnish parliamentary candidates' websites in the 2003 election campaign”, New Media \& Society 11(5), 835-854.

Strandberg, K. (2013). "A Social Media Revolution or Just a Case of History Repeating itself? The use of social media in the 2011 Finnish parliamentary elections", New Media \& Society, 15(8). Available at: http://nms.sagepub.com/content/early/2013/01/13/1461444812470612.abstract

Sudulich, M. L. and Wall, M. (2010). ““'Every little helps”: Cyber-campaigning in the 2007 Irish general election”, Journal of Information Technology \& Politics 7(4), 340-355.

Tenscher, J. (2013). "First- and second-order campaigning: Evidence from Germany", European Journal of Communication 28(3), 241-258. 